\title{
PEDAGOGO EMPRESARIAL: FUNÇÕES E METODOLOGIAS EMPREGADAS NA RESOLUÇÃO DE PROBLEMAS CORPORATIVOS
}

\section{ARTIGO ORIGINAL}

SILVA, Renata Santos ${ }^{1}$

SILVA, Renata Santos. Pedagogo Empresarial: Funções e metodologias empregadas na resolução de problemas corporativos. Revista Científica Multidisciplinar Núcleo do Conhecimento. Ano 05, Ed. 03, Vol. 06, pp. 90-102. Março de 2020. ISSN: 2448-0959, Link de acesso: https://www.nucleodoconhecimento.com.br/pedagogia/pedagogoempresarial

\section{RESUMO}

As funções e meios de atuação do pedagogo ainda são desconhecidos por muitas pessoas, o que constitui um dos fatores para a contratação de psicólogos nas empresas para exercerem atividades específicas daquele profissional. Tendo isso em vista, o presente artigo tem como objetivo apresentar as atribuições e algumas das ferramentas de trabalho do pedagogo (e.g. programas de ação) no meio corporativo, espaço no qual cabe a tal profissional melhorar as relações interpessoais, estimular a criatividade e a participação ativa e atender às demandas individuais e coletivas (e.g. capacitação técnica, melhor comunicação e estabelecimento da confiança entre os colaboradores). Metodologicamente, para o desenvolvimento do presente estudo, fezse um levantamento bibliográfico, assumindo-se as considerações de Gil (1994), Piletti (1995), Moscovici (1998), Eboli (2004), Holtz (2006), Lopes (2011) e Oliveira (2018) sobre os principais problemas da educação empresarial e Delors (1999), Libâneo (2001), Maron e Vieira (2002), Méndez (2002), Seitz (2005), Lopes; Trindade;

${ }^{1}$ Pós-graduação em Gestão Escolar e Pós-graduação em Pedagogia empresarial. 
Candinha (2009), Ribeiro (2010), ICE (2016) e Carvalho (2020) a respeito das competências, funções e instrumentos do pedagogo na empresa.

Palavras-chave: Pedagogia, empresa, educação, relação interpessoal, capacitação.

\section{INTRODUÇÃO}

No cenário brasileiro atual, a profissão de pedagogo tem sido fortemente associada ao âmbito escolar porque tal profissional lida com a educação, sendo raros os casos nos quais o encontramos, por exemplo, em hospitais e empresas. Todavia, como salienta Piletti (1995, p. 16): "Educação não se confunde com escolarização, pois a escola não é o único lugar onde a educação acontece. A educação também se dá onde não há escolas.". Desse modo, por desconhecer as atribuições do pedagogo, observa-se que muitas empresas geralmente contratam psicólogos para desempenharem funções próprias daquele profissional.

Tendo isso em vista, o objetivo geral do presente artigo é a reflexão e a demonstração da importância do pedagogo no cenário corporativo. Como objetivos específicos, podem ser elencados os seguintes:

1. indicar os principais problemas encontrados na educação corporativa e

2. reconhecer as competências, atribuições e instrumentos do pedagogo na resolução de problemas corporativos.

Para tanto, metodologicamente, será feito um levantamento bibliográfico sobre o tema. Serão assumidas as considerações dos seguintes autores: Gil (1994), Piletti (1995), Moscovici (1998), Eboli (2004), Holtz (2006), Lopes (2011) e Oliveira (2018) a respeito dos problemas da educação empresarial (objetivo específico (a) arrolado acima) e Delors (1999), Libâneo (2001), Maron e Vieira (2002), Méndez (2002), Seitz (2005), Lopes; Trindade; Candinha (2009), Ribeiro (2010), ICE (2016) e Carvalho (2020) sobre as funções e aptidões do pedagogo bem como os instrumentos empregados na resolução de problemas (objetivo específico (b)). 
Quanto à justificativa para a realização dessa investigação, constata-se que são inúmeros os trabalhos que abordam a importância e atribuições do pedagogo empresarial - para citar alguns, Oliveira (2002), Silva (2009), Mariano (2015), Lorensini (2015), Silva (2016), Almeida e Verloffa (2017) e Lopes (2017). Todavia, não se observa uma articulação com os problemas enfrentados atualmente no âmbito corporativo nem com os instrumentos que podem ser empregados pelo pedagogo para resolvê-los, sendo essa a relevância e o diferencial do presente estudo.

O presente artigo está dividido em seções. Na próxima, serão apresentados os principais problemas educacionais presentes no ambiente corporativo. Já na segunda, serão arroladas e comentadas as atribuições e competências do pedagogo. $\mathrm{Na}$ terceira seção, por seu turno, será apresentada e explicada a utilidade das ferramentas pedagógicas no âmbito corporativo. Por fim, na última seção, serão sintetizadas as principais conclusões advindas das reflexões feitas ao longo das seções.

\section{EDUCAÇÃO E PROBLEMAS NO AMBIENTE CORPORATIVO}

A educação é o processo de desenvolvimento das capacidades intelectuais e físicas dos indivíduos tendo em vista sua socialização, de modo que sejam aptos a interagir com o ambiente ao seu redor. Na maioria das vezes, pensa-se que a educação é restrita à esfera escolar, o que explica a errônea ideia de que pedagogos possam atuar somente naquele espaço. Como indica Libâneo (2001, p. 59):

Todos os educadores seriamente interessados nas ciências da educação, entre elas a Pedagogia, precisam concentrar esforços em propostas de intervenção pedagógica nas várias esferas do educativo para enfrentamento dos desafios colocados pelas novas realidades do mundo contemporâneo.

De fato, a educação mostra-se como um processo contínuo, ocorrendo em vários momentos e esferas da vida dos indivíduos: religiosa, familiar, acadêmica, empresarial 
etc., pois "[...] é uma construção contínua da pessoa humana, do seu saber, das suas aptidões, mas também da sua capacidade de discernir e agir" (DELORS, 1999, p.106).

No contexto atual, um dos objetivos finais da educação tem sido o desenvolvimento qualitativo e quantitativo dos indivíduos para a sua absorção pelo mercado de trabalho. Eboli (2004, p. 11) indica alguns fatores que contribuem para essa relação entre educação e empresas e ainda prevê uma tendência:

A educação tem hoje em dia legitimidade, pois há forte implicação no desenvolvimento econômico e na competitividade de um país e isso agrega às outras legitimidades. Assim sendo, fico inclinada a imaginar que serão as empresas que darão o tom do sistema educacional nos próximos tempos.

Na prática, porém, como indica Lopes (2011), verificam-se ainda muitas falhas no sistema educacional básico do país: falta de recursos e infraestrutura; altos índices de analfabetismo funcional nos adultos; desigualdade no acesso às oportunidades; deficiências na formação dos professores etc.

Nesse ponto, é interessante trazer à tona a seguinte consideração de Freire (apud LOPES, 2011, p. 45): "o professor não é uma pessoa na sala de aula e outra na vida. Ele é na sala de aula a consequência de uma história.". Estendendo essa afirmação para qualquer profissão, pode-se dizer que as atitudes dos profissionais são iguais tanto no seu meio de trabalho quanto fora dele por ser consequência da sua formação, ou seja, do seu processo educacional.

Desse modo, muitos funcionários exibem déficits oriundos da educação básica dificuldade de leitura e de expressão, de realização de cálculos básicos etc. -, cabendo às empresas suprimi-los. Por outro lado, no próprio ambiente corporativo, verifica-se o surgimento de problemas de relacionamento e de saúde pelo emprego de tecnologias. O uso da Internet e, por conseguinte, de e-mails, messenger, celulares etc. têm contribuído para o excesso de peso e obesidade; défices de atenção; agressividade e comportamentos antissociais; bullying e assédio moral; indução ao 
consumismo; confusão entre fantasia e realidade; depressão; prejuízo à criatividade e perda da privacidade. Isso pode ser constatado em Oliveira (2018)[2]:

O uso descontrolado da tecnologia causa prejuízos na vida das pessoas como um todo. Elas perdem o foco das coisas realmente importantes e têm uma qualidade das relações empobrecida, isso é pouco percebido. A pessoa perde o foco, fica mais distraída, retém menos informações e tem uma diminuição da memória.

Esses (e outros) problemas podem fomentar conflitos interpessoais que, por seu turno, não são exclusividade do meio corporativo. Discordâncias entre os indivíduos são comuns em qualquer ambiente, sendo motivadas por divergências de ideologias, de escolhas e de decisões. Assim, nessas situações, o foco deve recair sobre o espaço, a empresa, e não sobre os indivíduos. Além disso, os conflitos se mostram produtivos por permitirem a visualização de uma situação sob perspectivas distintas, sendo, de fato, perigosos quando não resolvidos, cedendo lugar à apatia, à falta de interesse e de motivação e ao conformismo por partes dos funcionários.

Uma prova de que as relações interpessoais são fundamentais para o meio corporativo é a crescente preocupação das empresas em treinarem os funcionários não só tecnicamente, mas também para que interajam e trabalhem em equipe, como observa Gil (1994, p. 63):

O treinamento nas empresas passou a abranger aspectos psicossociais do indivíduo. Assim, os programas de treinamento, além de visarem capacitar os trabalhadores para o desempenho das tarefas, passaram a incluir também objetivos voltados para o relacionamento interpessoal e sua interação a organização.

Sintetizando o que foi visto nessa seção, para além dos próprios problemas formativos, o meio corporativo em si pode contribuir para a emergência de outros nos seus colaboradores. Cabe, então, ao pedagogo intervir para que tal situação não adquira proporções que afetem a empresa em nível global. Feitas essas 
considerações, avancemos para a próxima seção, na qual serão listadas e comentadas as funções e competências desse profissional no meio corporativo.

\section{A PROFISSÃO DO PEDAGOGO NO AMBIENTE CORPORATIVO}

O escopo de atuação do pedagogo extrapola o âmbito escolar em virtude de ele ser o estudioso das ações educativas que, como visto anteriormente, ocorrem nos meios sociais, culturais e intelectuais do sujeito. Nas palavras de Libâneo (2001, p. 14):

Proponho que os profissionais da educação formados pelo curso de Pedagogia venham a atuar em vários campos sociais da educação, decorrentes de novas necessidades e demandas sociais a serem regulados profissionalmente. Tais campos são: as escolas e os sistemas escolares; os movimentos sociais; as diversas mídias, incluindo o campo editorial; a áreas da saúde; as empresas; os sindicatos e outros que se fizerem necessários.

Assim, para além de professores, pedagogos podem atuar como gestores, planejadores, formadores, instrutores, técnicos, consultores, orientadores etc. Eles podem ainda desenvolver atividades pedagógicas em órgãos públicos e privados ligados às empresas, à cultura, aos serviços de saúde, à alimentação e à promoção social.

No espaço empresarial, objeto de estudo desse artigo, a Pedagogia surgiu da necessidade de formação e preparação dos recursos humanos nas empresas, tendo em vista que tal setor é fundamental para o crescimento da organização. Assim, as metas do pedagogo empresarial são, dentre outras, as seguintes: qualificar os colaboradores; reconstruir conceitos básicos, como criatividade, espírito de equipe, autonomia emocional e cognitiva e melhorar o clima organizacional. Em poucas palavras, busca-se o crescimento pessoal e profissional dos funcionários.

Em termos práticos, com base em Maron e Vieira (2002), são as responsabilidades e as tarefas cotidianas do pedagogo na empresa: 
a) compreender e conduzir todos os colaboradores na diretriz dos objetivos humanos e empresariais;

b) gerar condições necessárias - por meio de reuniões, treinamentos, cursos, eventos, feiras, exposições etc. - para o desenvolvimento educacional e melhora da produtividade dos colaboradores;

c) indicar as atitudes e posturas mais adequadas das chefias em relação à equipe e vice-versa a fim de favorecer um ambiente agradável e positivo e que, por conseguinte, incentive a produtividade.

Discorramos sobre esses pontos elencados nos próximos parágrafos. No atual mundo globalizado, no qual o conhecimento muda à velocidade imensurável, as empresas têm exigido profissionais amplamente qualificados. Assim, mostra-se mais vantajoso o constante investimento em capital intelectual[3] dos colaboradores do que a contratação de novos, porque, nesse último caso, demanda-se um tempo para se adaptarem e esse período parado significa perda de dinheiro. "Quanto mais se investe no aperfeiçoamento do conhecimento já adquirido do funcionário da empresa, mais ele se torna valioso e essencial para a mesma". (LOPES; TRINDADE; CANDINHA, 2009, p. 29)

Outro problema constatado nas empresas é a não resolução de conflitos ou a indiferença nas relações interpessoais que geram efeitos negativos sobre os funcionários e, por extensão, sobre a empresa ao se enfezar os pilares corporativos: trabalho coletivo, autonomia e capacidade inventiva. A respeito da importância da boa relação entre colegas de trabalho, Moscovici (1998, p. 47) afirma:

Vale enfatizar, reiteradamente, que as relações interpessoais no grupo são tão ou mais importantes do que a qualificação individual para as tarefas. Se os membros relacionam-se de maneira harmoniosa, com simpatia e afeto, as probabilidades de colaboração aumentam muito, a sinergia pode ser atingida e resultados produtivos surgem de modo consistente. 
Por fim, observa-se ainda, da parte dos colaboradores, a falta de confiança em verbalizar dúvidas a respeito de como agir numa dada situação e, até mesmo, o desconhecimento sobre as próprias atribuições na empresa. Isso se dá por diversas razões: medo de perder o emprego; receio de gerar uma imagem negativa de si e temor de ser ridicularizado por ter dúvida.

Nessa conjuntura, é fundamental, então, a ação do pedagogo corporativo, que lança mão de estratégias e metodologias que proporcionem uma aprendizagem significativa e que provoquem mudanças no comportamento das pessoas. Isso porque parte-se da premissa básica de que há uma relação entre ser humano e ambiente, de maneira que um indivíduo melhor faz com que o espaço ao seu redor se torne melhor. Por exemplo, o pedagogo pode apresentar claramente, para cada funcionário, o perfil de sua função, as atividades inerentes à mesma e, ao fim, solicitar um feedback do que Ihe foi dito para verificar se os colaboradores entenderam corretamente o que terão de fazer, como e em qual tempo. Para além de melhorar a comunicação e as relações entre diferentes níveis, como entre gerente e funcionário, esse tipo de postura gera confiança no colaborador de sugerir ideias ou soluções para problemas que estejam ocorrendo na empresa. Essa mudança de comportamento constitui um exemplo de aprendizagem e, por conseguinte, de processo educacional, como se constata em Holtz (2006, p. 6):

Tanto a empresa como a Pedagogia agem em direção a realização de ideais e objetivos definidos, no trabalho de provocar mudanças no comportamento das pessoas. Esse processo de mudança provocada, no comportamento das pessoas em direção a um objetivo, chama-se aprendizagem. E aprendizagem é a especialidade da Pedagogia e do Pedagogo.

Em resumo, a percepção, o trabalho em equipe e o estabelecimento de prioridades em conformidade com a situação corporativa se mostram como competências fundamentais do pedagogo a fim de se aperfeiçoar os colaboradores tanto a nível profissional quanto pessoal. Feitas tais considerações, passemos para a próxima 
seção, na qual serão apresentadas as ferramentas empregadas pelo pedagogo no ambiente empresarial para solucionar problemas de diversas naturezas.

\section{ESTRATÉGIAS E FERRAMENTAS EMPREGADAS PELO PEDAGOGO}

Não há um roteiro de como o pedagogo deva agir numa dada situação porque as suas formas de atuação dependem do tipo de problema, da filosofia e da cultura empresarial e, principalmente, das suas experiências anteriores. Uma dada metodologia que foi aplicada com êxito, por exemplo, para resolver problemas de comunicação num setor pode não ser operante quando implementada em outro da mesma empresa.

Assim, como dito antes, uma das competências fundamentais desse profissional é a percepção, que the possibilitará adequar, ou até mesmo, construir ferramentas adequadas a um dado contexto. Por exemplo, em uma situação desânimo dos colaboradores, o pedagogo deverá buscar estratégias que possibilitem o estímulo de toda a equipe, valorizando os pontos que cada um tem de melhor, o que pressupõe um bom conhecimento prévio a respeito do perfil dos funcionários.

Uma segunda observação a ser feita é que algumas das ferramentas que serão citadas a seguir têm origem no trabalho pedagógico escolar. A possibilidade de aplicálas no meio corporativo se dá porque, como dito anteriormente, a empresa também representa um espaço de aprendizagem e, por conseguinte, de educação.

Feitas tais ressalvas, apresentemos três dos instrumentos que auxiliam o trabalho do pedagogo. O primeiro deles são os programas de ação por meio dos quais se aperfeiçoam e estimulam as faculdades das personalidades dos colaboradores, possibilitando que esses sejam capazes de apresentarem questões, de construírem hipóteses explicativas a determinadas situações e de identificarem ações alternativas. Seitz (2005, p. 117) assim define os programas de ação: 
Como orientação geral o programa de ação deve conter as especificações das providências, prioridades e respectivas ações a serem empreendidas, sendo indispensável a indicação dos responsáveis pelas mesmas no formato de quem vai fazer o que, quando, a que custo, e com que resultados (margem de contribuição e lucro entre outros).

O segundo instrumento do pedagogo são os planos de ação, partindo-se de uma situação-problema ou necessidade corporativa. Tais planos são compostos por doze etapas:

a) apresentação - trata-se da discussão acerca do problema ou da necessidade previamente estabelecida juntamente com as propostas interventivas oferecidas pelos próprios funcionários;

b) justificativa - momento no qual se ressalta a importância de sanar o problema, baseando-se na relevância social e científica da proposta e tendo-se claro o resultado que se pretende alcançar;

c) objetivos - concernem ao estabelecimento de indicadores para a avaliação e a adoção de novos procedimentos e de novas ações. Dividem-se em objetivos gerais, que são as diretrizes principais para a ação e as diretrizes orientadoras para o projeto, e objetivos específicos, que detalham cada uma das etapas para se alcançarem os resultados desejados;

d) metas - permitem quantificar os objetivos e estabelecer padrões para ação;

e) indicadores - facilitam os processos de acompanhamento, avaliação e controle das relações entre os resultados alcançados e aquilo que foi planejado;

f) conteúdo - diz respeito aos principais temas que serão desenvolvidos pelo projeto e ao conhecimento prévio acerca do perfil e tipo de função exercida pelos colaboradores. Auxilia as indicações a serem feitas pelo instrutor; 
g) metodologia - refere-se aos métodos de tratamento frente a problemas diversos, estando em adequação com as necessidades/finalidades e contextos específicos da empresa;

h) atividades - a escolha dessas deve estar em conformidade com as indicações dos objetivos, das metas, dos requisitos e das metodologias. A listagem das principais atividades a serem desenvolvidas permite estabelecer/ visualizar a sua relação com a proposta e a função organizacional a qual se destina;

i) fluxo de trabalho - para sua elaboração, toma-se como ponto de partida a especificação das atividades mais importantes;

j) cronograma - é elaborado em função do diagrama de fluxo de trabalho e representa a listagem das etapas e das respectivas previsões de tempo e de execução;

k) avaliação - refere-se à explicitação das atividades realizadas para garantir o êxito do projeto. A avaliação estabelece um juízo de valor sobre algo realizado a partir de um acompanhamento constante de todo o processo desencadeado desde a concepção até a realização/ operacionalização da proposta ou do projeto. Também consta da interpretação dos resultados obtidos;

I) custos - constituem um demonstrativo detalhado dos recursos necessários à execução do projeto, como, por exemplo, recursos humanos, materiais e financeiros. Por outros termos, a previsão de custos engloba as pessoas envolvidas no projeto, os equipamentos e as instalações necessárias para operacionalização e a reserva técnica destinada a cobrir eventuais reajustes financeiros ou atividades não programadas.

Carvalho (2020, p. 35) assim define os planos de ação:

Bastante utilizado nas empresas para atingir metas, o plano de ação é útil para que você torne realidade aquela grande ideia ou o projeto com que tanto sonha, ou até mesmo para que algumas tarefas possam ser desempenhadas de maneira mais organizada no seu dia a dia. 
É interessante notar que as duas ferramentas até então apresentadas - a saber, programas de ação e planos de ação - se mostram relacionadas. Por exemplo, se, numa empresa, os funcionários se mostram receosos em fazer questionamentos, o pedagogo pode elaborar e implementar um Plano de Ação para um dado setor e, posteriormente, adaptá-lo para os demais setores na forma de um Programa de Ação. Constatamos tal relação na seguinte passagem: "[Programa de Ação] é um instrumento operacional individual que trata dos meios e processos e que desdobram as estratégias traçadas no Plano de Ação em ações" (ICE, 2016, p. 35)

Por fim, como último exemplo de instrumento empregado pelo pedagogo, pode-se citar as tarefas de acesso democrático ao conhecimento que visam qualificar ou aperfeiçoar a capacitação dos colaboradores em conformidade com as ideias e metas da empresa. Trata-se da produção de conhecimento, investigação e reflexão, cernes da Pedagogia não só na empresa, mas em qualquer esfera social. A respeito da importância do acesso democrático ao conhecimento, Méndez (2002, p. 62) constata:

Uma educação entendida como processo de seleção e de exclusão restringe as possibilidades de se ter acesso ao conhecimento [...] contrariamente, se a educação é entendida como um processo de acesso democrático ao conhecimento e à ascensão das pessoas, o enfoque muda de origem.

Antes de encerrar a presente seção, é interessante citar mais um exemplo. Em várias empresas, é comum ouvir-se reclamações sobre as reuniões, por vezes caracterizadas como desnecessárias ou improdutivas; o que gera desânimo e descrença em relação a quem as promove - tanto que, quando possível e dependendo de quem a conduz, alguns funcionários tendem a evitar participar delas. Lançando mão de programas de ação, o pedagogo pode, então, reverter essa imagem negativa ao propor, por exemplo, a seleção de um grupo distinto para cada reunião; auxiliar na elaboração de um roteiro com pontos interessantes de serem debatidos coletivamente; criar um clima de confiança e autonomia que estimulem os funcionários a compartilharem suas ideias e opiniões e, por fim, demonstrar a importância das ações de cada equipe e funcionário naquele período de tempo. 
Nesse ponto, cabe, então, apresentar a seguinte consideração de Ribeiro (2010, p. 11) acerca das ferramentas de trabalho e dos resultados esperados da intervenção pedagógica:

[...] cabe à Pedagogia a busca de estratégias e metodologias que garantam uma melhor aprendizagem/apropriação de informações e conhecimentos, tendo sempre como pano de fundo a realização de ideias e objetivos precisamente definidos. Tem como finalidade principal provocar mudanças no comportamento das pessoas de modo que estas melhorem tanto a qualidade do seu desempenho profissional quanto pessoal.

Na presente seção, procurou-se demonstrar que o trabalho pedagógico responde às demandas contextuais, isto é, não há um guia de como agir perante a um problema ou necessidade que surja. A percepção e as experiências anteriores do pedagogo são seu ponto de partida para a escolha ou adaptação dos instrumentos de trabalhos, dos quais foram abordados três: programas de ação, planos de ação e tarefas de acesso democrático ao conhecimento. Para finalizar, na seção a seguir, sintetizaremos as principais conclusões advindas das ideias apresentadas ao longo desse estudo.

\section{CONSIDERAÇÕES FINAIS}

Desmitificando a ideia de que, por lidar com a educação, o trabalho do pedagogo se limita às escolas, partiu-se do pressuposto de que aquela se dá em todos os momentos da vida do indivíduo e esferas sociais, sendo uma delas o meio corporativo, objeto de estudo desse artigo. Conforme apresentado na seção 1, em tal espaço, como qualquer outro, há problemas que podem ser oriundos dos indivíduos (e.g. os formativos) e também das relações ali estabelecidas (e.g. conflitos interpessoais), não devendo ser tidos como algo negativo, mas como uma forma de aprendizagem. Todavia, é importante que o pedagogo interfira e resolva por completo tais conflitos para não gerar como consequências, por exemplo, apatia e conformidade, essas sim desastrosas para os indivíduos e para empresa como um todo. 
Ainda a respeito desse profissional, foram arroladas como suas incumbências e aptidões na seção 2: desenvolver o trabalho de formação e atualização dos funcionários; identificar necessidades coletivas e individuais, bem como possíveis dificuldades do processo de trabalho (conflitos, desinteresse e problemas comunicativos) e estimular a criatividade e participação ativa dos colaboradores (tomada de decisões, indicação de problemas e sugestões etc.).

Finalmente, a fim de atingir tais objetivos e, consequentemente, solucionar os problemas corporativos, ao longo da seção 3 , apresentaram-se os seguintes instrumentos que podem ser empregadas pelo pedagogo: programas de ação; planos de ação e tarefas de acesso democrático ao conhecimento. Todavia, fez-se a ressalva de que esses não são únicos nem úteis para qualquer situação, porque o pedagogo, a partir da sua percepção e experiência, precisa estabelecer qual instrumento é mais adequado para cada contexto.

Em resumo, pode-se dizer que a contratação desse profissional representa um investimento em capital intelectual que, a curto prazo, melhora a área de Recursos Humanos ao desenvolver e potencializar as capacidades dos funcionários. Como consequência, a longo prazo, contribui-se para a produtividade e para a melhoria da imagem organizacional.

\section{REFERÊNCIAS}

CARVALHO, Rafael. Plano de ação: como fazer um mapa para conquistar seus objetivos. Na Prática.org, 2020. Disponível em <https://www.napratica.org.br/planode-acao/>. Acesso em: 04/02/2020.

DELORS, Jacques. Educação: um tesouro a descobrir, 3를 Edição. São Paulo: Cortez, 1999. 240p. ISBN: 9788524918452.

EBOLI, Marisa. Educação Corporativa no Brasil: Mitos e Verdades, $2^{\underline{a}}$ Edição. São Paulo: Gente, 2004. 280p. ISBN: 9788573124231. 
GIL, Antônio Carlos. Administração de recursos humanos: um enfoque profissional, 1aㅡ Edição. São Paulo: Atlas, 1994. 167p. ISBN: 9788522411344.

HOLTZ, Maria Luiza Marins. Lições de pedagogia empresarial. São Paulo: MH Assessoria Empresarial S/C Ltda, 2006. 64p. Disponível em <http://valdata.com.br/downloads/CURSOS/Li\%C3\%A7\%C3\%B5es\%20de\%20Peda gogia\%20empresarial.pdf >. Acesso em: 04/02/2020.

INSTITUTO DE CORRESPONSABILIDADE PELA EDUCAÇÃO. Tecnologia de Gestão Educacional.

Princípios e conceitos. Planejamento e Operacionalização. Pernambuco: ICE, 2016. Disponível em:

$<$ http://www.arcoverde.pe.gov.br/zaap/kcfinder/upload/files/arquivos/processoseletivo/8-mg-tecnologia-de-gestao-educacional.pdf>. Acesso em: 04/02/2020.

LIBÂNEO, José Carlos. Pedagogia e Pedagogos, para Quê?, 4르 Edição. São Paulo: Cortez, 2001. 208p. ISBN: 9788524906978.

LOPES, Izolda. Pedagogia Empresarial - formas e contextos de atuação, $4^{a}$ Edição. Rio de Janeiro: Wak Editora, 2011. 126p. ISBN: 9788588081673.

LOPES, Izolda; TRINDADE, Ana Beatriz; CANDINHA, Marcia Alvim. Pedagogia Empresarial. Forma e contextos de atuação, $3^{\text {a }}$ edição. Rio de Janeiro: Wak Editora, 2009. 128p. ISBN 978-85-88081-67-3

MARON, Neusa Maria; VIEIRA, Alboni Marisa Dudeque Pianovski. O pedagogo e a aprendizagem empresarial. Tuiuti: Ciência e Cultura. Curitiba, número 28, p.11-44, mar/2002.

Disponível

em:

$<$ https://www.academia.edu/2007027/O_pedagogo_ea_aprendizagem_empresarial>. Acesso em: 04/02/2020. ISSN: 2176-896X

MÉNDEZ, Juan Manoel Alvarez. Avaliar para conhecer examinar para excluir Volume 2, 1르 edição. Porto Alegre: Artmed, 2002. 136p. ISBN: 978-8573079159. 
MOSCOVICl, Fela. Equipes dão certo: a multiplicação do talento humano, $4^{\mathrm{a}}$ edição. Rio de Janeiro: Jose Olympio, 1998. 240p. ISBN: 8503005247.

OLIVEIRA, Sibele. Uso excessivo de tecnologia pode causar insônia, dores e prejudicar visão. UOL, São Paulo, 2018. Disponível em: $<$ https://www.uol.com.br/vivabem/noticias/redacao/2018/07/21/quais-problemas-desaude-o-uso-excessivo-de-tecnologia-pode-causar.htm>. Acesso em: 10/11/2019.

PILETTI, Claudino. Didática geral, 19ª Edição. São Paulo: Ática S.A., 1995. 258p. ISBN: 8508026986.

RIBEIRO, Amélia Escotto do Amaral. Temas Atuais em Pedagogia Empresarial: Aprender para ser competitivo, $3^{a}$ edição. Rio de Janeiro: Walk, 2010. 168p. ISBN: 9788588081444.

SEITZ, Helgo Max. O Planejamento Estratégico de Marketing e o Plano de Negócios. eGesta - Revista Eletrônica de Gestão de Negócios, São Paulo, volume 1, número 3, p. 91 - 127, 2005. Disponível em: < https://www.unisantos.br/mestrado/gestao/egesta/artigos/46.pdf >. Acesso em: 10/11/2019. ISSN 1809-0079.

STEWART, Thomas. Capital Intelectual, $2^{2}$ edição. Rio de Janeiro: Editora Campus, 1998. 237p. ISBN: 85-352-0247-1.

\section{APÊNDICE - REFERÊNCIAS DE NOTA DE RODAPÉ}

2.

$<$ https://www.uol.com.br/vivabem/noticias/redacao/2018/07/21/quais-problemas-desaude-o-uso-excessivo-de-tecnologia-pode-causar.htm>.

3. "O capital intelectual constitui a matéria intelectual - conhecimento, informação, propriedade intelectual, experiência - que pode ser utilizada para gerar riqueza." (STEWART, 1998, p. xiii). 
Enviado: Dezembro, 2019.

Aprovado: Março, 2020. 